\title{
Prototype Alarm Pendeteksi Banjir Dengan Water Level Sensor Funduino Berbasis Mikrokontroler Arduino Uno
}

\author{
Ratna Herawati*1, Wis nu Sanjaya ${ }^{2}$, Syah Ronny Wijaya ${ }^{3}$ \\ ${ }^{1}$ Program Studi Sistem Informasi, STMIK AUB, Surakarta, Indonesia \\ ${ }^{2}$ Program Studi Teknik Informatika, Universitas Boyolali, Indonesia \\ ${ }^{3}$ Program Studi Teknik Komputer, STMIK AUB, Surakarta, Indonesia \\ e-mail: *1 ratna.herawati@stmik-aub.ac.id, ${ }^{2}$ wisnuksl@stmik-aub.ac.id
}

\begin{abstract}
Abstrak
Ruang terbuka hijau yang semakin berkurang, eksploitasi hutan secara besar-besaran, sampah-sampah semakin menumpuk ditambah dengan perubahan cuaca y ang ekstrim dapat memicu terjadinya bencana alam. Salah satunya adalah banjir yang dapat menghambat aktivitas, menimbulkan berbagai penyakit serta kerugian secara materi. Oleh karena itu untuk mengurangi dampak kerugian yang ditimbulkan oleh banjir adalah adanya sistem a tau a lat pendeteksi banjir dengan alarm. Prototype alarm pendeteksi banjir dengan sensor water level Funduino berbasis Arduin Uno ini dibuat untuk membantu masyarakat dalam me min imalisir kerugian yang ditimbulkan oleh banjir dan dapat dipantau melalui $L C D$.

Pada penelitian ini digunakan sensor water level Funduino untuk mengetahui a danya air. Data dari sensor berupa sinyal digital yang akan diproses oleh Mikrokontroler Arduino Uno kemudian ditampilkan pada LCD sebagai display dan akan ditandai dengan bunyi a larm daribuzzer.

Berdasarkan pengujian yang telah dilakukan baik pada mekanik maupun pada elektronika yang telah dibuat serta melihat tujuan dari penelitian, mak a dapat disimpulkan bahwa alat telah diuji dan dapat digunakan untuk membantu masyarakat maupun penjaga pintu air.
\end{abstract}

Kata kunci-Arduino Uno, Sensor, Water Level, Funduino, Banjir, Alarm, LCD, Buzzer

\begin{abstract}
Green open space dwindling, forest exploitation on a large scale, the garbage accumulating coupled with extreme weather changes can trigger natural disasters. One of them is a flood that can inhibit activity, causing various diseases and material losses. Ther efore, to reduced the impacts of losses caused by flooding is the presence of a system or flood detector with an alarm. Prototype flood detector alarm with a water level sensor based Funduino Uno Arduino was created to assist the public in minimizing losses caused by flooding and can be monitored via the LCD.

In this study used the water level sensor Funduino to know the existence of water. Data from sensors in the form of digital signals that will be processed by Arduino Uno Microcontroller then displayed on the LCD as a display and will be marked with alarm sound from the buzzer.

Based on the tests that have been done both on machines and electronics that have been made and see the purpose of research, it can be concluded that the tool has been tested and can be used to help the community and the entrance.
\end{abstract}

Keywords-Arduino Uno, Sensor, Water Level, Funduino, Flood, Alarm, LCD, Buzzer

Received April 3, 2019; Revised April 24, 2019; Accepted June 11, 2020 


\section{PENDAHULUAN}

Ruang terbuka hijau yang semakin berkurang, eksploitasi hutan secara besar-besaran, sampah-sampah semakin menumpuk ditambah dengan perubahan cuaca yang ekstrim dapat memicu terjadinya bencana alam. Salah satunya adalah banjir yang dapat menghambat aktivitas, menimbulkan berbagai penyakit serta kerugian secara materi. Menurut data dari Badan Nasional Penanggulangan Bencana Indonesa (BNPB), banjir merupakan bencana alam dengan frekuensi kejadian terbanyak dibandingkan dengan bencana alam lainnya sekaligus bencana alam yang menelan korban terbanyak ke-3 dalam periode tahun 1815-2014 (https://bnpb.go.id/). Salah satu yang sering terjadi banjir adalah masyarakat yang tinggal didaerah sekitar bendungan. Ini dikarenakan tidak adanya sistem pendeteksi banjir ditempat tersebut. Sehingga pintu air tidak di buka dan masyarakat terlambat mengungsi dan membuat kerugian materi dan lain-lain. Kerugian - kerugian ini dapat dikurangi apabila masyarakat sudah mengetahui terlebih dahulu bahwa akan terjadi banjir. Oleh karena itu diperlukan suata alat/sistem peringatan dini yang dapat membaca salah satu tanda datangnya banjir.

Karena untuk mengetahui akan terjadinya banjir, masyarakat harus pergi melihat ketinggian air secara langsung sehingga hal ini tidak efektif. Karena itulah, akan dibuat sebuah alat yang dapat menginformasikan akan terjadinya banjir dengan output alarm bertanda.

Pada penelitian ini akan digunakan sensor water level yaitu Funduino dengan prinsip reed switch untuk mengetahui perubahan level ketinggian permukaan air. Data dari sensor berupa sinyal digital yang akan diproses oleh Mikrokontroler Arduino Uno kemudian ditampilkan pada LCD sebagai display dan akan ditandai dengan bunyi alarm dari buzzer. Dari uraian di atas maka tugas akhir ini diberi judul "Prototipe Alarm Pendektesi Banjir Dengan Sensor Water Level Funduino Berbasis Mikrokontroler Arduino Uno".

\section{METODE PENELITIAN}

\subsection{Kerangka Penelitian}

Metode penelitian pembuatan alat pendeteksi level ketinggian air adalah sebagai berikut:

1. Studi Literatur

Yaitu tentang teori-teori dan makalah yang terkait dengan penelitian pembuatan alat alarm pendeteksi banjir.

2. Perancangan Perangkat Keras

Meliputi perancangan rangkaian sensor level, rangkaian sistem minimum mikrokontroller, rangkaian display indikator level ketinggian dan rangkaian untuk membatasi level ketinggian air.

3. Perancangan Perangkat Lunak

Digunakan untuk mengendalikan batas level ketinggian air tertentu dengan batas level ketinggian air.

4. Pembuatan

Yaitu melakukan pembuatan alat dari bahan-bahan yang telah disediakan dan terkumpul menjadi sebuah alat dengan program yang dinginkan.

\subsection{Blok Diagram}

Diagram blok merupakan gambaran umum mengenai prinsip kerja yang akan dibuat. Secara umum cara kerja alat pendeteksi ketingigian air ini dapat dilihat pada diagram blok yang ditunjukkan pada Gambar 1. 


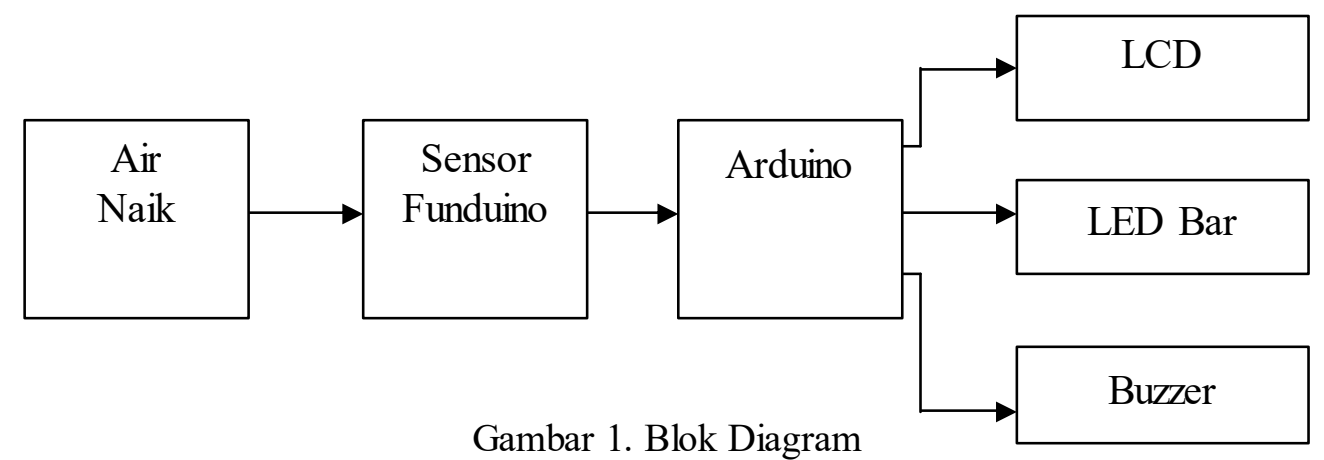

\subsection{Diagram Alir}

Diagram alir (flowchart) adalah gambaran secara grafik yang terdiri dari simbol-simbol dari algoritma-algoritma dalam suatu program yang menyatakan arah alur suatu program, diagram alir merupakan dasar dari pemograman.

Diagram alir perlu dibuat sesuai dengan perangkat keras yang dibuat, agar program yang dibuat terstruktur dan jelas. Selain itu juga alur program yang akan dibuat jelas. Diagram alir permbuatan prototype alarm pendeteksi banjir dapat dilihat pada Gambar 2.

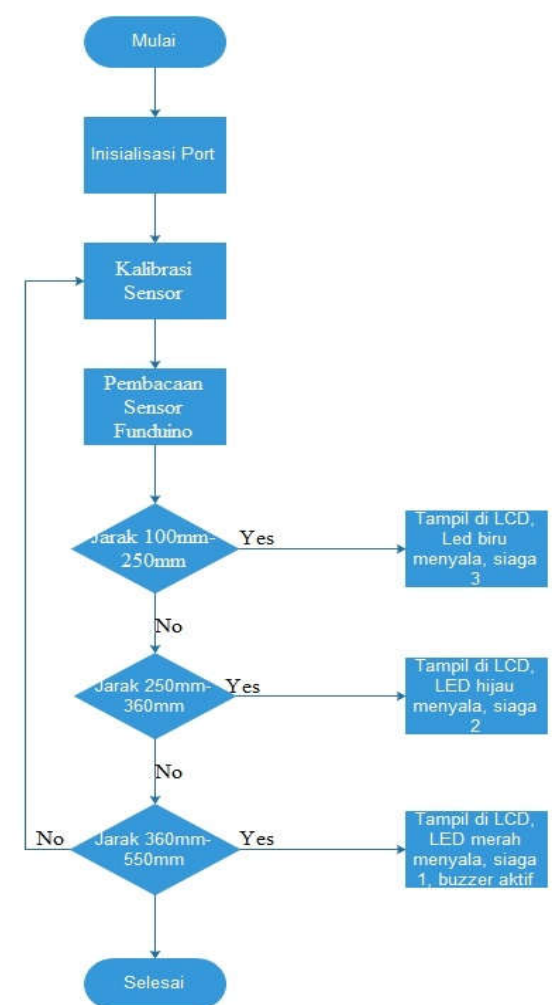

Gambar 2. Alur flowchart

\subsection{Rangkaian Keseluruhan}

Prototipe Alarm Pendeteksi Banjir dengan Water Level Sensor Funduino ... (Ratna Herawati) 


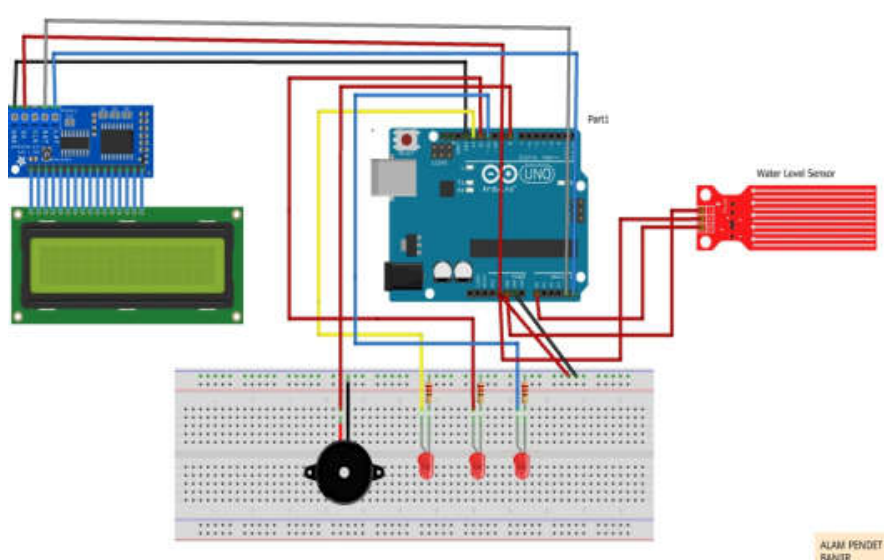

Gambar 3. Rangkaian Keseluruhan

Gambar 3 menunjukkan gambar secara keseluruhan dimana rangkaian terdapat Arduino, Buzzer, LCD, LED dan Water Level Funduino. Dengan power supply usb yang terhubung dengan laptop atau power bank akan mengaliri tegangan ke masing-masing komponen yang ada.

\subsection{Perancangan Mekanik}

Perancangan mekanik dibuat untuk membantu dalam membuat sebuah prototype alat. Perancangan mekanik juga dapat mendukung kinerja alat. Pada penelitian ini penulis menggunakan acrylic untuk membuat wadah atau tempat untuk prototype. Perancangan mekanik dapat dilihat pada Gambar 4 berikut.

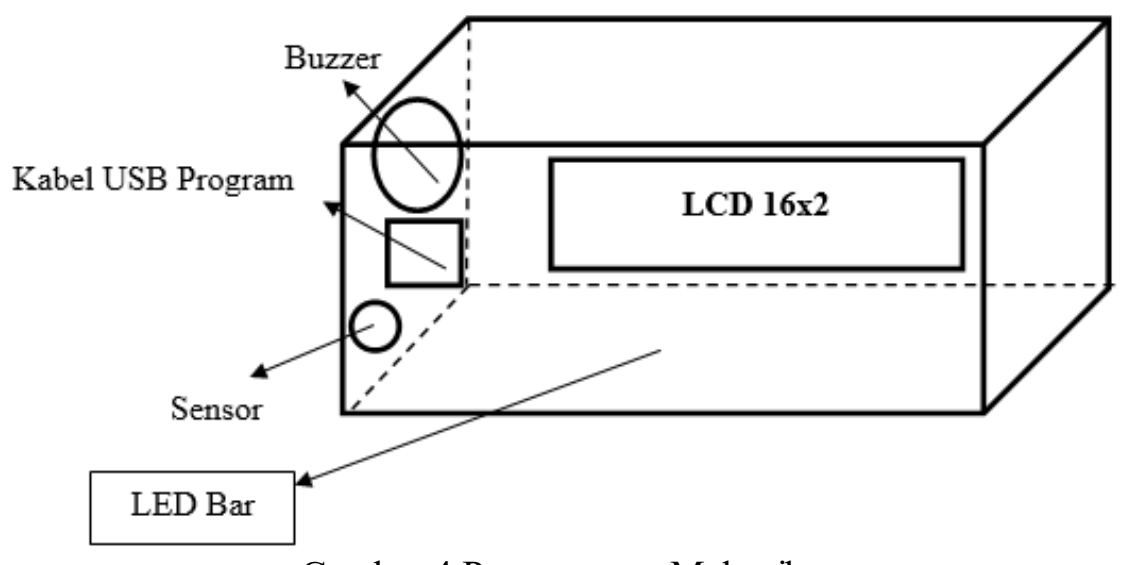

Gambar 4 Perancangan Mekanik

\section{HASIL DAN PEMBAHASAN}

\subsection{Pengujian Board Arduino}

Pengujian Board Arduino menggunakan I/O digital pada pin D0-D13. Pengujian ini dilakukan dengan memasukkan program sederhana (Aktive-Passive Buzzer) dan mengukur tegangan pada masing-masing pin I/O dengan periode $100 \mathrm{~ms}$ low dan $100 \mathrm{~ms}$ high secara bergantian.

Pada arduino dan buzzer pada breadboard yang tersedia, kemudian hubungkan pin 12 arduino dengan pin ground buzzer dan pin tegangan pada breadboard, kemudian tes rangkaian buzzer arduino. 


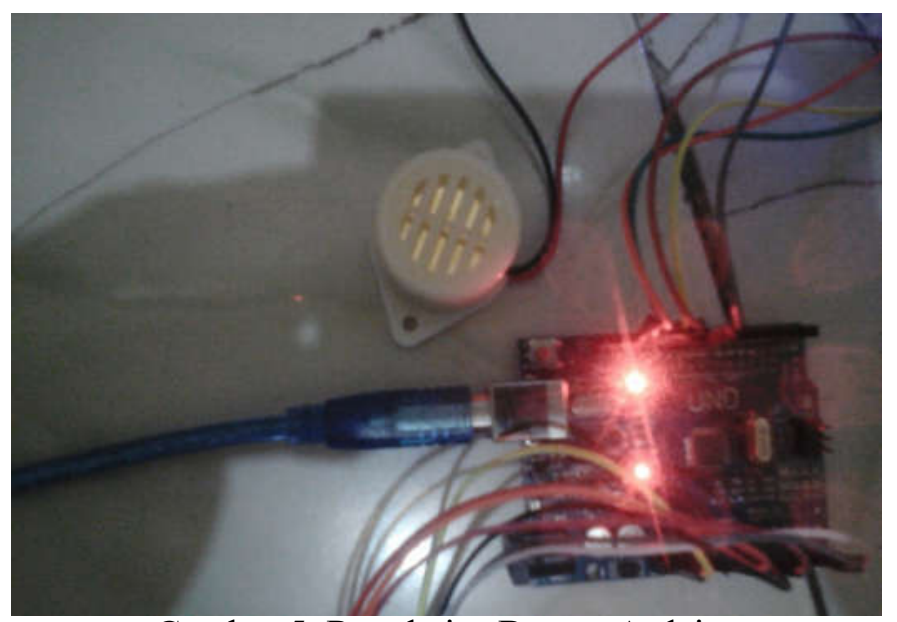

Gambar 5. Rangkaian Buzzer Arduino

Tabel 1 dibawah ini menunjukkan hasil pengujian pada rangkaian buzze Arduino.

Tabel 1. Tabel hasil pengujian Board Arduino

\begin{tabular}{|c|c|c|c|}
\hline No & Pin digital I/O & Tegangan Low & Tegangan High \\
\hline 1 & D0 & 0 & $5.1 \mathrm{~V}$ \\
\hline 2 & D1 & 0 & $5.1 \mathrm{~V}$ \\
\hline 3 & D2 & 0 & $5.1 \mathrm{~V}$ \\
\hline 4 & D3 & 0 & $5.0 \mathrm{~V}$ \\
\hline 5 & D4 & 0 & $5.1 \mathrm{~V}$ \\
\hline 6 & D5 & 0 & $5.0 \mathrm{~V}$ \\
\hline 7 & D6 & 0 & $5.0 \mathrm{~V}$ \\
\hline 8 & D7 & 0 & $5.1 \mathrm{~V}$ \\
\hline 9 & D8 & 0 & $5.1 \mathrm{~V}$ \\
\hline 10 & D9 & 0 & $5.0 \mathrm{~V}$ \\
\hline 11 & D10 & 0 & $5.0 \mathrm{~V}$ \\
\hline 12 & D11 & 0 & $5.9 \mathrm{~V}$ \\
\hline 13 & D12 & 0 & $5.1 \mathrm{~V}$ \\
\hline 14 & D13 & 0 & 5 \\
\hline
\end{tabular}

Tegangan output yang dihasilkan pada Arduino untuk dapat menjalankan komponen antara $5 \mathrm{v}$ DC $-9 \mathrm{v}$ DC. Dari hasil pengujian pada tabel 4.1 didapatkan tegangan rata-rata $\mathrm{pin}=5 \mathrm{v}$ DC, tetapi pin tegangan output pada pin D11 kurang 0.1v DC.

\subsection{Pengujian Sensor Water Level Funduino}

Sensor ini akan bekerja jika mendapat suplay tegangan sebesar 5v DC. Dimana tegangan 5v DC dihubungkan dengan konektor Vcc dan ground pada sensor. Pada keluaran (output) dihubungkan pada Arduino Pin A0, jika sensor mendeteksi adanya air kemudian mengubahnya ke sinyal analog dan mengirimnya ke mikrokontroller. Berikut Gambar 6 sistem program dan uji coba secara langsung. 


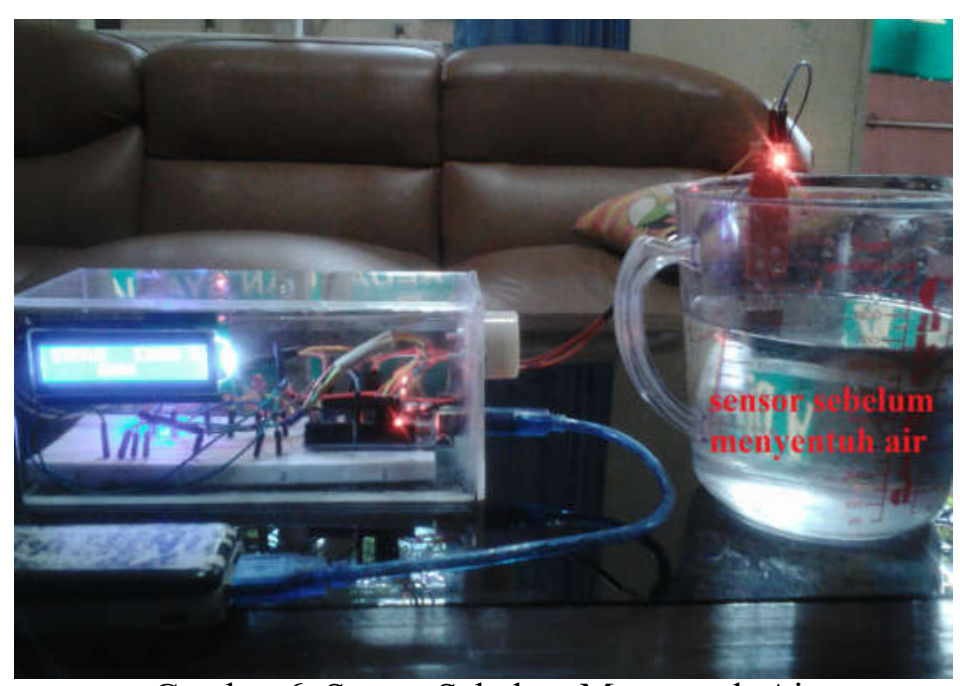

Gambar 6. Sensor Sebelum Menyentuh Air

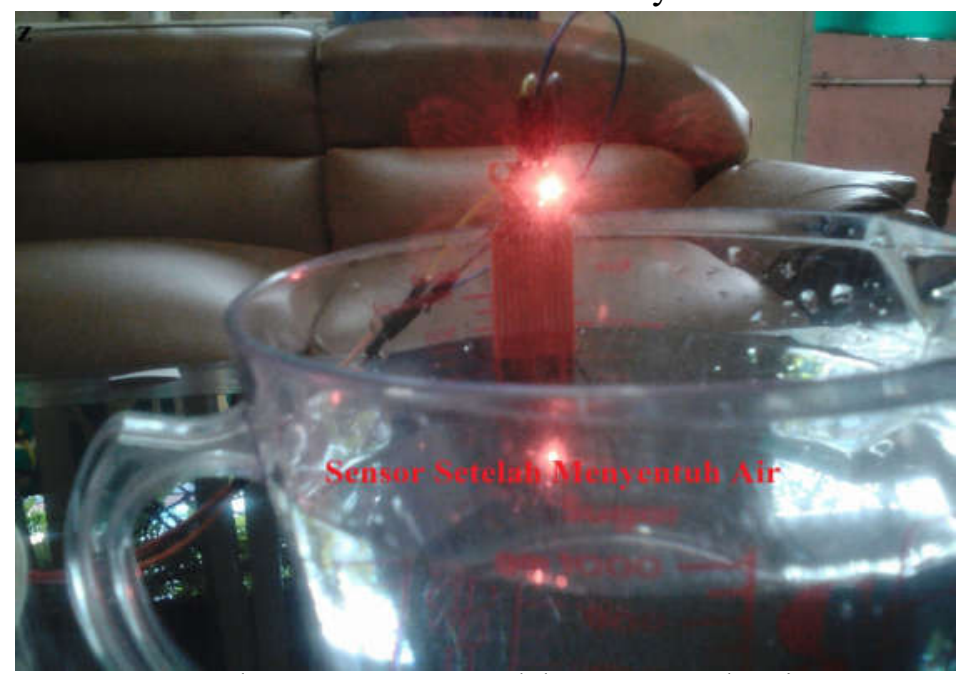

Gambar 7. Sensor Setelah Menyentuh Air

Tabel 2 dibawah ini merupakan hasil pengujian Sensor Water Level Funduino.

Tabel 2 Hasil pengujian sensor water level funduino

\begin{tabular}{|c|c|c|c|}
\hline No & Hasil Analog Sensor & Kondisi & Ke terangan \\
\hline 1 & $<100-<250$ & Aman & $\begin{array}{c}\text { Led Biru Menyala } \\
\text { Buzzer Mati }\end{array}$ \\
\hline 2 & $>250-<360$ & Waspada & $\begin{array}{c}\text { Led Hijau Menyala } \\
\text { Buzzer Mati }\end{array}$ \\
\hline 3 & $>360-<550$ & Bahaya & $\begin{array}{c}\text { Led Merah Menyala } \\
\text { Buzzer Hidup }\end{array}$ \\
\hline
\end{tabular}

Dari hasil pengujian di atas menunjukkan jika sensor terkena air maka secara otomatis LCD akan menampilkan informasi kondisi level air sesuai yang telah diprogram pada Arduino.

\subsection{Pembahasan}

Pada pembahasan alat secara keseluruhan langkah pertama jika air menyentuh sensor, sensor akan membaca sesuai tingkat ketinggian air yang telah diprogram dan diuplod ke Arduino setelah itu terdapat keluaran atau output dari LCD sebagai penampil peringatan, LED sebagai tanda tinggat tinggi air dan buzzer sebagai alarm sesuai dengan keluaran program seperti Gambar 8. 


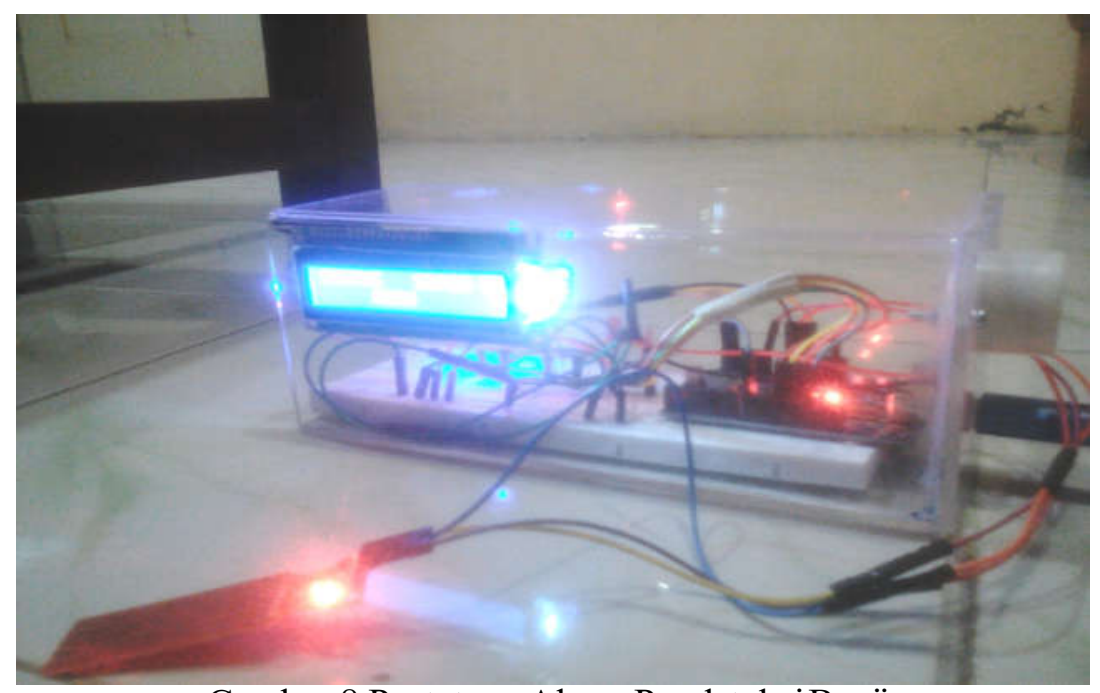

Gambar 8 Prototype Alarm Pendeteksi Banjir

Dari pengujian yang di amati dapat disimpulkan bahwa alat berfungsi dengan baik dan tidak ada kerusakan. Penerapan konsentrasipada sensor sangat berperan pada penentuan tingkat tinggi air. Karena jika sensor tidak dapat membaca maka sistem tersebut tidak akan berjalan dengan baik.

\section{KESIMPULAN}

Pada penelitian ini dilakukan perancangan dan design Protoype Alarm Pendeteksi Banjir dengan Water Level Sensor Funduino Berbasis Mikrokontroller Arduino Uno. Dari hasil penelitian ini dapat disimpulkan sebagai berikut:

1. Penggunaan alat ini digunakan untuk mengetahui tinggi air atau sebagai alarm ketika adanya banjir dengan memanfaatkan Water Level Sensor Funduino sebagai pemantau tinggi air, ketika air menyentuh sensor lalu diolah ke Mikrokontroller setelah itu didapatkan data dan menampilkannya ke LCD dan buzzer sebagai output.

2. Sistem akan langsung menghidupkan buzzer setelah sensor mencapai siaga 1.

3. Jarak air saat menyentuh sensor dapat diubah melalui Mikrokontroller Arduino Uno.

4. Kepekaan sensor sangat mempengaruhi kinerja alat.

5. Dari proses pengujian alat ini maka dapat disimpulkan bahwa untuk kerja rangkaian alat ini baik dan sesuaiyang diharapkan.

\section{SARAN}

Saran yang didapatkan penulis berikan untuk pengembangan sistem ini selanjutnya antara lain:

1. Pemberitahuan tidak hanya menggunakan alarm namun dapat ditambahkan dengan sistem auto SMS broadcast sehingga masyarakat yang terdapat didaerah rawan banjir dapat segera mengetahui informasi bahwa akan terjadi banjir.

2. Menambahkan informasi tentang kecepatan dan debit air.

3. Melakukan pengujian di air yang mengalir.

Prototipe Alarm Pendeteksi Banjir dengan Water Level Sensor Funduino ... (Ratna Herawati) 


\section{DAFTAR PUSTAKA}

[1] Arduino. (2017, Oktober) ARDUINO UNO. [Online]. http//arduino.cc

[2] http://www.leselektronika.com/2012/06/liguid-crystal-display-lcd-16-x-2.html diakses tanggal 11 Oktober 2017.

[3] Iswanto, Belajar Sendiri Microcontroller AT90S2313 Dengan BASIC Compiler: Andi, Yogyakarta, 2009

[4] Moh. Ibnu Malik \& Mohammad Unggul Juwana, (2009), ANEKA PROYEK Mikrokontroler PIC16F84/ A, Jakarta: PT. Elex Media Komputindo

[5] Nurul Afdhal 2006. Sistem Pemantauan Ketinggian Air Secara Real Time

[6] Berbasis Mikrokontroller AT89C2051. Darussalam, Banda Aceh; Teknik Elektro Universitas Syiah Kuala

[7] Nusantara Elektronik: Sensor Air Funduino http://elektronik-nusantara.co.id Diakses tanggal 12 September 2017

[8] Sulaiman, Arif 2012. ARDUINO: Mikrocontroller bagi pemula hingga Mahir. https://widuri.raharja.info/index.php/SI11334669938, Skripsi, STMIK Raharja, Tangerang.

[9] Susilo, Deddy. 2009. 48 Jam Kupas Tuntas Mikrokontroler MCS51 \& AVR, Yogyakarta: CV. ANDI OFFSET

[10] Syahwill, Muhammad, 2013. Panduan Mudah Simulasi dan Praktik Mikrokontroler Arduino: CV. ANDI OFFSET, Yogyakarta.

[11] Zona elektro, Resistor karakteristik dan fungsinya http://zonaelektro.net/resistorkarakteristik-nilai-dan-fungsinya/ diakses tanggal 11 Oktober 2017

[12] Zulfy Budiarso dkk 2011. Sistem Monitoring Tingkat Ketinggian Air Bendungan Berbasis Mikrokontroller 